\title{
Burden and vulnerability of hypertension in a rural population of Patna, Bihar, India
}

\author{
Rashmi Singh ${ }^{1}$, Ranjeet K Sinha ${ }^{2}$, Chandra Mani ${ }^{3}$, Ritu Singh ${ }^{4}$, Ranabir Pal $^{5}$
}

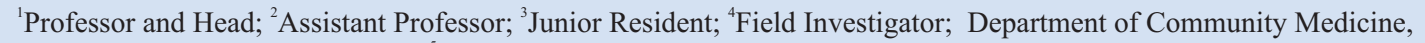
Patna Medical College, Patna, India. 'Department of Community Medicine, Sikkim Manipal Institute of Medical Sciences, Gangtok, Sikkim, India.

\section{Abstract}

Population based studies on hypertension from rural Bihar have not been reported earlier. We conducted a study to find the prevalence and the risk factors of hypertension in a rural adult population. In this cross-sectional community based study, 1083 men and women, aged 30 years and above, residing at 10 randomly selected villages of Phulwarisarif Block of Patna District of Bihar were recruited. Using house to house interviews with a semi-structured pretested schedule, the sociodemographic risk factors were recorded. Hypertension and pre-hypertension were classified using JNC-VII criteria. Overall prevalence of hypertension was 23.73\%; among them mean systolic and diastolic blood pressures were $144.8 \pm 17.14$ and $89.04 \pm 9.25 \mathrm{~mm}$ of $\mathrm{Hg}$ respectively. Among those who were hypertensive, the age cluster was higher (50.6 \pm 12.7 years) than those who were normotensive (43.8 \pm 12.4 years) with a significant male preponderance. Hypertension was significantly associated with a higher body mass index, waist-to-hip ratio, along with the sedentary lifestyle. However, there was not an association with consumption of alcohol and smoking. The study highlighted the need for initiation of high risk hypertension screening in rural Bihar as the awareness on and its risk factors was very low.

Key words: Hypertension, Prevalence, Risk factors, Awareness.

\section{Introduction}

Presently hypertension is one of the most significant global public health problems and also the most common cardiovascular health crisis in both developed and developing countries. The prevalence of the hypertension has been rising in India and other developing countries in the recent times but understanding and efforts to intervene remains miserably poor. Hypertension per se is a quiet disorder that remains usually asymptomatic until it does immense harm to the body in the form of "Target Organ Damage". Hence WHO has coined the term the "Silent Killer". Studies also have reported hypertension as a significant public health problem in urban as well rural areas of India. $^{1-3}$

The current estimated frequency of hypertension in India is $10-15 \%$ in the rural population and $25-30 \%$ in the urban population. ${ }^{3}$ Hypertension is also directly responsible for $57 \%$ of all strokes deaths and $24 \%$ of coronary heart disease deaths in India and also remains to be the leading cause of blindness, renal failure and congestive heart failure. Previously thought as a disease of urban well off population, a rural infringement is nowadays increasingly being reported. The probability of escalating cardiovascular diseases in rural India is a public health concern and not

\section{Practice points}

- Population based studies on hypertension from rural Bihar have not been reported earlier.

- Overall prevalence of hypertension was $23.73 \%$ with a significant male preponderance.

- High prevalence of pre-hypertension was also noted $(11.17 \%)$

- Higher BMI, waist: hip ratio along with the sedentary lifestyle was significantly associated with hypertension.

- There is a need for initiation of high risk hypertension screening in rural India.

much research had been done about the burden and risk factors in rural areas. ${ }^{4-7}$

To compound the problem, a great majority of the rural population in India has suboptimal access to healthcare and is not conscious enough to seek health care until sickness causes much distress.

Correspondence: Dr. (Professor) Ranabir Pal, Professor, Department of Community Medicine, Sikkim Manipal Institute of Medical Sciences and Central Referral Hospital, $5^{\text {th }}$ Mile, Tadong, Gangtok, Sikkim- 737 102, India. Email: ranabirmon@yahoo.co.in. 
We are yet to find published studies on the prevalence of hypertension with the associated risk factors for effective futuristic approach of the problem in rural Bihar. Therefore this population based study was undertaken in rural Phulwarisharif block of Patna district, Bihar.

\section{Methods}

\section{Study area and subjects}

This community-based cross sectional study was conducted in the villages of Phulwarisarif Block of Patna District of Bihar from August 2009 till July 2010. Inclusion criteria were all men and women above 30 years present in their houses at the time of visit of the team from Patna Medical College.

\section{Sampling procedure}

With an anticipated $10 \%$ prevalence, using proportion estimates and allowable error of $20 \%$, the sample size for this study was calculated as $990 .^{3}$ Taking $10 \%$ as non response error, we tried to reach a size of 1089 . From the list of 53 villages under the Phulwarisarif Block of the district, 10 villages were randomly selected from four sectors by a conventional lottery method. Eligible participants were enrolled using the random number table from electoral roll of election commission of India obtained from Panchayat office. All these eligible individuals, identified in each of the selected villages, were met through house to house visits by specifically assigned teams and at least 100 members were enrolled from each village by which we were able to reach 1083 participants.

\section{Data collection procedure}

Institution Ethics Committee of Patna Medical College approved the study. The health workers informed and motivated the families to participate in the study along with the scope of future intervention, if necessary. All the participants were informed of the purpose of the study and were ensured strict confidentiality. The participants were given the option not to participate in the study if they wanted. After collection of informed consent, a semistructured pretested questionnaire was administered. Blood pressure and its determinants such as age, sex, nature of work, smoking and alcohol consumption, educational status, family history and awareness about hypertension and its complications were recorded. For the BMI calculation, height was measured using a portable height measuring stand and weight was recorded using a set of bathroom scales; for the waist/hip ratio, waist and hip circumference was measured in centimeters using a single non-stretchable measuring tape. Subjects were then allowed to take rest for five minutes in a sitting position, their hand rested and supported on arm chair at the heart level. Blood pressure was measured by single investigator using the pulse obliteration and auscultation method using the standardized and calibrated mercury sphygmomanometer. Those with systolic blood pressure more than or equal to $140 \mathrm{~mm}$ of $\mathrm{Hg}$ and diastolic blood pressure more than or equal to $90 \mathrm{~mm}$ of $\mathrm{Hg}$, those on antihypertensive medication, or those with history of hypertension were classified as hypertensive, as per the Seventh Report of the Joint National Committee on Prevention, Detection, Evaluation and Treatment of High Blood Pressure (JNC VII) criteria. ${ }^{8}$

\section{Data analysis}

Data were entered and analyzed using SPSS Version 16. Percentages and proportions were used, and the chi square test was used to find any significance.

\section{Results}

Of the total of 1,083 participants, $23.73 \%$ were hypertensive (95 \% CI, 22.88-24.58) and the number increased significantly as the age of the study population increased $\left[\chi^{2}=54.94, \mathrm{df}=4, \mathrm{p}=<0.0001\right]$. Males had a significantly higher prevalence in all age groups $[32.39 \%$ vs. $20.65 \%$, $\mathrm{P}<0.05]$ except the 50-59 year group. Sex differentials were also found to be statistically significant [Male: $\chi^{2}=12.928$, $\mathrm{df}=4, \mathrm{p}=0.012$ and Female: $\left.\chi^{2}=33.630, \mathrm{df}=4, \mathrm{p}=0.0001\right]$ (Table 1).

As the blood pressure level of subjects was further classified according to JNC VII criteria ${ }^{8}$, apart from the 257 (23.73\%) hypertensive individuals, $532(49.12 \%)$ were categorized as pre-hypertensive out of which $121(11.17 \%)$ were in the target range of 130-139 or 85-89 mm of Hg (Table 2).

The mean age of hypertensive subjects $(50.6 \pm 12.7$ years $)$ was higher than the normotensive population (43.8 112.4 years). Systolic and diastolic blood pressure (mean \pm SD)

Table 1: Distribution of hypertensive subjects according to age and sex

\begin{tabular}{|c|c|c|c|c|c|c|}
\hline $\begin{array}{c}\text { Age } \\
\text { yrs }\end{array}$ & Screened & Hypertensive (\%) & Screened & Hypertensive (\%) & Total & $\begin{array}{c}\text { Total } \\
\text { screened }\end{array}$ \\
hypertensive (\%) \\
\hline $30-39$ & 77 & $15(19.48)$ & 332 & $43(12.95)$ & 409 & $58(14.18)$ \\
\hline $40-49$ & 34 & $11(32.35)$ & 206 & $39(18.93)$ & 240 & $50(20.83)$ \\
\hline $50-59$ & 55 & $15(27.27)$ & 146 & $43(29.45)$ & 201 & $58(28.85)$ \\
\hline $60-69$ & 84 & $37(44.05)$ & 92 & $31(33.70)$ & 176 & $68(38.63)$ \\
\hline$>70$ & 34 & $14(41.18)$ & 23 & $9(39.13)$ & 57 & $23(40.35)$ \\
\hline Total & 284 & $\mathbf{9 2}(\mathbf{3 2 . 3 9 )}$ & $\mathbf{7 9 9}$ & $\mathbf{1 6 5}(\mathbf{2 0 . 6 5 )}$ & $\mathbf{1 0 8 3}$ & $\mathbf{2 5 7}(\mathbf{2 3 . 7 3 )}$ \\
\hline
\end{tabular}


were $144.8 \pm 17.14 \mathrm{~mm}$ of $\mathrm{Hg}$ and $89.04 \pm 9.25 \mathrm{~mm}$ of $\mathrm{Hg}$ respectively in hypertensive subjects as compared to $116.4 \pm 9.7$ and $75.3 \pm 7$ respectively in non-hypertensive subjects (Table 3 ).

Table 2: Participants category based on the JNCVII Criteria

\begin{tabular}{|c|c|c|c|}
\hline Category & $\begin{array}{c}\text { Mean SBP } \\
\text { and DBP } \\
(\mathrm{mm} \text { of } \mathrm{Hg})\end{array}$ & Frequency & Percent \\
\hline Normal & $<120$ and $<80$ & 294 & 27.15 \\
\hline Pre hypertensive & $\begin{array}{c}120-129 \\
\text { and/or } 80-84\end{array}$ & 411 & 37.95 \\
\hline Pre hypertensive & $\begin{array}{c}130-139 \text { or } \\
85-89\end{array}$ & 121 & 11.17 \\
\hline Hypertensive & $\begin{array}{c}>=140 \text { or } \\
>=90\end{array}$ & 257 & 23.73 \\
\hline
\end{tabular}

$\mathrm{SBP}=$ Systolic blood pressure, $\mathrm{DBP}=$ Diastolic blood pressure

Among the hypertensive patients, 59\% were obese and 39\% pre obese. Increase of BMI was significantly associated with the risk of hypertension $\left[\chi^{2}=41, \mathrm{df}=3, \mathrm{p}=0.0001\right]$.

Table 3: Mean age and blood pressure of hypertensive and normotensive subjects

\begin{tabular}{|l|c|l|l|}
\hline $\begin{array}{l}\text { Hypertensive } \\
\text { (N= 257) }\end{array}$ & Age (yrs) & 50.66 & 12.714 \\
\hline & SBP (mm of Hg) & 144.82 & 17.141 \\
\hline $\begin{array}{l}\text { Normotensive }(\mathrm{mm} \text { of } \mathrm{Hg}) \\
\text { (N= 826) }\end{array}$ & Age (yrs) & 43.04 & 9.256 \\
\hline & SBP (mm of Hg) & 116.42 & 12.401 \\
\hline & DBP (mm of Hg) & 75.33 & 7.002 \\
\hline
\end{tabular}

$\mathrm{SBP}=$ Systolic blood pressure, $\mathrm{DBP}=$ Diastolic blood pressure

Prevalence of hypertension was significantly higher $(35.90 \%)$ in those doing sedentary work $\left[\chi^{2}=9.92, \mathrm{df}=2\right.$, $\mathrm{p}=0.007]$. The differences in waist-hip ratios of hypertensive and non hypertensive subjects were found to be statistically significant. [48.14\% in $>1$ vs. $22.44 \%$ in $<1$; $\left.\chi^{2}=18.72, \mathrm{df}=1, \mathrm{p}<0.001\right]$. However, it is apparent that hypertension was not associated with the consumption of alcohol $\left[\chi^{2}=1.364, \mathrm{df}=4, \mathrm{p}=0.850\right]$ and smoking $\left[\chi^{2}=5.550\right.$, $\mathrm{df}=4, \mathrm{p}=0.235] \quad$ (Table 4). Furthermore, $129(11.9 \%)$ individuals had a family history of hypertension out of which 32 (25.1\%) developed hypertension. Nearly half of the study population $(498,46 \%)$ was illiterate and only 249 $(23 \%)$ participants were aware about hypertension or its complications. However, no associations of family history and literacy with hypertension were found.

\section{Discussions}

Our study on the rural population documented the high prevalence of both hypertension and pre-hypertension, and their association with BMI, Waist-hip ratio and lifestyle factors. This links to the growing epidemic of cardiovascular disease, with a high prevalence of prehypertension shown among both sexes. Coupled with a lack of awareness and ignorance about the complications of hypertension, the situation is conducive to the perpetuation of the disease among the rural population in one of the poorer states in India.

Various studies estimated that differential prevalence rates are due to different cut off marks in determining the level of hypertension and differing age groups in the study population. ${ }^{9}$ The prevalence of hypertension in this study was $23.73 \%$ which is higher than the other Indian studies conducted in rural areas. Although our sample was random, the small sample size of the study may be the reason for higher prevalence. ${ }^{10-12}$ A study conducted in rural Andhra Pradesh noted that the mean systolic blood pressure was 116 $\mathrm{mm}$ of $\mathrm{Hg}$, diastolic blood pressure $73 \mathrm{~mm}$ of $\mathrm{Hg}$; the prevalence of hypertension was $20.3 \%{ }^{7}$ In a multi-centric study in rural India in18 states among people aged 20-69 years the age standardized prevalence of hypertension was $20 \%$ and $22 \%$ for men and women respectively. ${ }^{13}$ While Das et al. ${ }^{9}$ reported $24.9 \%$ of hypertension and $35.8 \%$ and $47.7 \%$ pre-hypertension in systolic and diastolic groups respectively in West Bengal, Yadav et al. ${ }^{14}$ reported 32.2\% hypertension and $32.3 \%$ pre-hypertension from Lucknow in the rural Central India.

According to $\mathrm{JNC} \mathrm{VII}^{8}$, a group of pre-hypertensive people are to be targeted for primary prevention. ${ }^{8}$ The overall proportion of this group was $49 \%$ in the study participants with $11.17 \%$ in the target range. The probable reason for the higher prevalence of hypertension among study subjects with higher BMI is that obese individuals tend to have higher BP levels because weight increases cardiac output proportionally and also increased the peripheral resistance of arterioles. ${ }^{8}$ A positive association was observed between BMI and development of hypertension by other Indian researches also.'

Central obesity was significantly associated with hypertension in the present study similar findings were reported by Yadav et al..$^{14}$ and Kokiwar and Gupta. ${ }^{15}$ A strong and statistically highly significant association between hypertension and $\mathrm{W} / \mathrm{H}$ ratio was also observed; similar findings were demonstrated by White et al ${ }^{16}$ and Widgren et $a l .{ }^{17}$ The probable reason for the higher prevalence of hypertension among subjects with $=1$ waist: hip may be due to impact of visceral (central) lipid accumulation on blood pressure level through several mechanisms of metabolic syndrome. $^{14-17}$

In an ICMR Indian Council of Medical Research study (ICMR) on the tea garden workers in Dibrugarh, hypertension was the most commonly observed health 
Table 4: Distribution of study subjects according to risk factors

\begin{tabular}{|c|c|c|c|}
\hline BMI* & Hypertensive & Non - Hypertensive & Total \\
\hline$\geq 18.5$ & $130(18 \%)$ & $574(82 \%)$ & $704(65 \%)$ \\
\hline $18.6 \quad 24.9$ & $74(29 \%)$ & $179(71 \%)$ & $253(23 \%)$ \\
\hline 25.029 .9 & $43(39 \%)$ & $66(61 \%)$ & $109(10 \%)$ \\
\hline$\geq 30$ & $10(59 \%)$ & $7(41 \%)$ & $17(1.5 \%)$ \\
\hline Total & $257(24 \%)$ & $826(76 \%)$ & $1083(100 \%)$ \\
\hline \multicolumn{4}{|c|}{ Nature of Work* } \\
\hline Hard Work & $120(25.26 \%)$ & $355(74.74 \%)$ & $475(43.86)$ \\
\hline Moderate & $109(20.57 \%)$ & $421(79.43 \%)$ & $530(48.94 \%)$ \\
\hline Sedentary & $28(35.90 \%)$ & $50(64.10 \%)$ & $78(7.20 \%)$ \\
\hline Total & $257(23.73 \%)$ & $826(76.27 \%)$ & $1083(100 \%)$ \\
\hline \multicolumn{4}{|c|}{ Waist : hip ratio* } \\
\hline$<1$ & $231(22.44 \%)$ & $798(77.55 \%)$ & $1029(95 \%)$ \\
\hline$\geq 1$ & $26(48.14 \%)$ & $28(51.85 \%)$ & $54(4.98 \%)$ \\
\hline Total & $257(23.73 \%)$ & $826(76.26 \%)$ & $1083(100 \%)$ \\
\hline \multicolumn{4}{|c|}{ Alcohol Intake } \\
\hline Yes & $41(28.27 \%)$ & $104(71.72 \%)$ & $145(13.38 \%)$ \\
\hline No & $226(24.09 \%)$ & $712(75.90 \%)$ & $938(86.61 \%)$ \\
\hline Total & $257(23.73 \%)$ & $826(76.27 \%)$ & $1083(100 \%)$ \\
\hline \multicolumn{4}{|l|}{ Smoking } \\
\hline Yes & $10(45.45 \%)$ & $12(54.54 \%)$ & $22(2.03 \%)$ \\
\hline No & $257(23.73 \%)$ & $804(75.77 \%)$ & $1061(97.96 \%)$ \\
\hline Total & $257(23.73 \%)$ & $826(76.27 \%)$ & $1083(100 \%)$ \\
\hline
\end{tabular}

*Significant

problem. ${ }^{18}$ In a recent study at Puducherry by Bharati et al. ${ }^{19}$, the overall hypertension in older generations was $47.7 \%$ (male: $37.0 \%$, female: $55.7 \%$ ). This significantly increased with advancing ages; high-normal to grade-3 hypertension was significantly higher in the females. A sedentary lifestyle, vegetarian diet and tobacco addiction were also found to be significantly associated with hypertension, though previous studies in South India reported a lesser prevalence $(14 \%){ }^{19,20}$ In a study in rural Varanasi, the overall prevalence of hypertension was $11.25 \%$. $^{21}$ Researchers from Sevagram reported a $3.41 \%$ prevalence in the rural population while a higher hypertension prevalence rate was observed in females $(4.6 \%)$ in contrast to males $(2.9 \%)$. $^{22}$ Indian researchers reported that hypertension increased with increasing age, with wider variations of hypertension of up to $50 \%$ hypertension among the older population. ${ }^{23-26}$ Wilking et $a .^{27}$ observed that the prevalence of isolated systolic hypertension appears to be greater for women than for men, whereas a WHO Report ${ }^{28}$ noted a $56 \%$ prevalence. In a community-based cross-sectional study in Aurangabad, Maharashtra the overall prevalence of hypertension in the study subjects was $7.24 \%$, higher in females $(7.92 \%)$ as compared with males $(6.55 \%)$ and hypertension was significantly associated with age, sex, BMI, smoking, alcohol consumption. ${ }^{29}$ A significantly higher blood pressure was noted among randomly selected fishermen of coastal West Bengal (mean age 22.4), who have more physical fitness (cardiovascular fitness) and muscle mass, but lower percentage of body fat than the sedentary population. ${ }^{30}$

Cardiovascular diseases are the foremost causes for premature death in India. In a review of Indian epidemiological studies of past 50 years, the researchers noted that hypertension had increased gradually in rural areas. ${ }^{31}$ Facts from developed countries show that these can be considerably reduced by means of population-based policies. A multi-factorial comprehensive move towards global prevention of cardiovascular disease for the low and middle income countries has been recommended by the proponents of prevention. ${ }^{31,32}$

The strength of the study was that in spite of a rural background and the absence of an affluent lifestyle, 
hypertension is becoming more prevalent which warrants that these populations should also be brought into the ambit of preventive care to the reduce risks of cardiovascular disease. The mean age of hypertensive subjects was higher than the normotensive population in our study with a male preponderance. An assessment of the known risk factors noted that hypertension was significantly associated with the risk factors of age, the male sex, the sedentary nature of work, obesity and an increased waist/hip ratio. Though the results are eloquent, we had several limitations. First, as the sample was small and drawn from one limited geographic area within Patna district, the results cannot properly be generalized to the national population. On the other hand, with lesser error the sample would have been unmanageable for us in the resource poor settings. Secondly, because of the cross-sectional design, this study had limited extrapolative value. Thirdly, given the lack of awareness, literacy, and indifference to health of the study subjects, the probability of missing information and erroneous recall cannot be excluded. Lastly, smoking and alcohol intake, literacy and family history were not found to be significantly associated with hypertension in this study population. This may be possibly due to the fact that information regarding these may not have been elucidated suitably. These are all limitations of our study. In the future, study highlighting all the multifaceted factors causing hypertension in rural population should be conducted. We also need to develop various surveillance programs to address the increasing health burden of the various noncommunicable diseases that are prevalent in Bihar.

\section{Conclusion}

To sum up, it is now desirable that screening programs for hypertension should be taken up in rural areas of Bihar because the majority do not have access health care facilities or do not avail them. The JNC-VII criteria ${ }^{8}$ seek to identify people at risk of developing hypertension to bring them into treatment or preventive regimens. Along with the presence of risk factors, the population most vulnerable to hypertension and other risk factors can be identified to minimize target organ damage, cardiovascular risks and chronic disability in rural population.

Due to the stress and tension inherent within the altering lifestyle patterns, there is a changing trend in the overall prevalence of hypertension. This study brings out the burden of hypertension and vulnerability of this rural population to the risk of developing lifestyle diseases, hence highlighting the importance of integrating hypertension screening into primary health care. For a substantial impact on this burden, unique preventive health care strategies specific to the rural population need to be clearly formulated and tested. Behavior change, and communication supported by screening is important for early detection and management of hypertension and to prevent any associated complications that may arise.

\section{Disclosure}

The authors report no conflicts of interest in this work.

\section{References}

1. Gupta R. Rethinking Diseases of Affluence; Coronary Heart Disease in Developing Countries. South Asian J Prev Cardiol 2006; 10: 65-78.

2. WHO. Heart Beat: The Rhythm of Health Report on World Health Day. $7^{\text {th }}$ April, 1991. Geneva: World Health Organization, 1992.

3. Gupta R. Trends in hypertension epidemiology in India. J Hum Hypertension 2004; 18:73-8.

4. Shah B, Gupta R, Mathur P, Saxena M, Agrawal RP, Bhardwaj A, et al. An action plan for noncommunicable disease prevention, surveillance, management and control in economically deprived Indian states: Lessons from Rajasthan. South Asian J Prev Cardiol 2006; 10:5-45.

5. Prakash C, Deewania, R Gupta. Hypertension in South Asians. South Asian J Prev Cardiol 2004; 8: 144-8.

6. Antezana FS. Epidemiologic aspects of hypertension in the world. 1996. www.gfmer.ch/TMCAM/ Hypertension/Epidemiologic aspects hypertension world.htm (accessed Oct 2011).

7. Chow C, Cardona M, Raju PK, Iyengar S, Sukumar A, Raju R, et al. Cardiovascular disease and risk factors among 345 adults in rural India--the Andhra Pradesh Rural Health Initiative. Int J Cardiol 2007;116:180-5.

8. Chobanian AV, Bakris GL, Black HR, Cushman WC, Green LA, Izzo JL Jr, et al. Seventh report of the Joint National Committee on Prevention, Detection, Evaluation, and Treatment of High Blood Pressure. Hypertension 2003; 42:1206-52.

9. Das K, Sanyal K, Basu A. A study of urban community survey in India; Growing trend of high prevalence of hypertension in individuals. Int JMed Sci 2005;2:70-8.

10. Kumar P. Choudhary V. Epidemiology and study of hypertension in rural Rajasthan. Indian Heart $J$ 1991;43:43-4.

11. Gupta R, Sharma S, Gupta VP, Gupta KD. Smoking and alcohol intake in rural Indian population and correlation with hypertension and coronary heart disease prevalence. J Assoc Phys India 1995;43:253-8.

12. Yuvraj BY, Nagendra Gowda MR, Umakant AG. Prevalence, awareness, treatment and control of hypertension in rural areas of Davanagere. Indian $J$ Community Med 2010;35:138-41.

13. Kinra S, Bowen LJ, Lyngdoh T, Prabhakaran D, Reddy KS, Ramakrishnan L, et al. Sociodemographic patterning of non-communicable disease risk factors in rural India: a cross sectional study. BMJ 2010; 341:c4974.

14. Yadav S, Boddula R, Genitta G, Bhatia V, Bansal B, 
Kongara S, et al. Prevalence and risk factors of prehypertension and hypertension in an affluent north Indian population. Indian J Med Res 2008;128:712-20.

15. Kokiwar PR, Gupta SS. Prevalence of hypertension in a rural community of central India. Int J Biol Med Res $2011 ; 2: 950-3$.

16. White FM, Pereira LH, Garner JB. Association of body mass index \& waist: hip ratio with hypertension. CMAJ $1986 ; 135 ; 313-20$.

17. Widgren BR, Herlitz H, Wikstrand J, Sjostrom L, Berglund G, Andersson OK. Increased waist/ hip ratio, metabolic disturbances, and family history of hypertension. Hypertension 1992;20; 563-8.

18. Medhi G K, Hazarika N C, Borah P K, Mahanta J. Health problems and disability of elderly individuals in two population groups from same geographical location. J Assoc Physicians India 2006; 54: 539-44.

19. Bharati DR, Pal R, Kar S, Rekha R, Yamuna TV. Ageing in Pudduchery, South India an overview of morbidity profile. J Pharm Bioallied Sci. 2011;3: 53742.

20. Purty AJ, Bazroy J, Kar M, Vasudevan K, Veliath A, Panda P. Morbidity Pattern Among the Elderly Population in the Rural Area of Tamil Nadu, India. Turk JMed Sci 2006;36:45-50.

21. Shankar R, Tondon J, Gambhir IS, Tripathi CB. Health status of elderly population in rural area of Varanasi district. Indian J Public Health 2007; 51:56-8.

22. Jajoo N, Kalantri P, Gupta P, Jain P, Gupta K. Prevalence of Hypertension in Rural Population around Sevagram, MGM, Wardha. J Assoc Phys India 1993;41:422-4.

23. Kishore S, Garg BS. Sociomedical problems of aged population in a rural of Wardha district. Ind J Public Health 1997;41:43-8.
24. Garg B S, Gupta S C, Mishra V N, Singh R B. A medico-social study of aged in Urban area. Ind Med Gazette 1982;16:90-5.

25. Prakash R, Choudhary S, Singh US. A study of morbidity pattern among geriatric population in an urban area of Udaipur, Rajasthan. Indian J Community Med 2004; 24:35-40.

26. Prakash O, Gupta LN, Singh VB, Singhal AK, Verma KK. Profile of psychiatric disorders and life events in medically ill elderly: experiences from geriatric clinic in Northern India. Int J Geriatr Psychiatry 2007; 22:1101-5.

27. Wilking SVB, Belanger A, Kannel WB, D'Agostino RB, Steel K. Determinants of isolated systolic hypertension. JAMA 1988; 260:3451-5.

28. WHO. Epidemiology and prevention of cardiovascular diseases in elderly people. Report of a WHO study group. WHO Technical Report Series 853. Geneva: World Health Organization, 1995.

29. Todkar SS, Gujarathi VV, Tapare VS. Period Prevalence and Sociodemographic Factors of Hypertension in Rural Maharashtra: A Cross-Sectional Study. Indian J Community Med. 2009;34:183-7.

30. Sengupta P, Sahoo S. Evaluation of the Health status of fishers: Prediction of cardiovascular fitness and anaerobic power. World J Life Sci Med Res 2011;1:2530.

31. Gupta R. Recent trends in coronary heart disease epidemiology in India. Indian Heart $J$ 2008; 60(2 Suppl B): B4-18.

32. Gupta R, Guptha S, Joshi R, Xavier D. Translating evidence into policy for cardiovascular disease control in India. Health Res Policy Syst 2011;9:8. 